\title{
Agua y desarrollo urbano en la Castilla medieval: aportaciones a su estudio en la ciudad de Guadalajara
}

\author{
Water and Urban Development in Medieval Castile: \\ A Study of the City of Guadalajara
}

\author{
Javier Plaza de Agustín ${ }^{1}$ \\ Escuela de doctorado UNED \\ Plaza_deagustin@yahoo.es
}

Recibido: $18 / 01 / 2016$

Aceptado: 04/03/2016

\begin{abstract}
RESUMEN
Uno de los elementos críticos del urbanismo castellano en la Edad Media era el acceso a recursos hídricos que pudieran servir para el abastecimiento humano. En función del clima, la orografía, y las infraestructuras heredadas de épocas anteriores, cada ciudad y villa del reino trató de buscar la mejor manera de asegurar el suministro de agua para sus vecinos. A lo largo de este trabajo se analiza la forma en la que el concejo de Guadalajara, así como los principales poderes religiosos y nobiliarios de la ciudad, fueron trazando la red de abastecimiento urbano durante la Baja Edad Media, a partir de las fuentes del paraje conocido como El Sotillo, y cómo realizaron la explotación económica del cauce del río Henares en las cercanías del municipio. El agua, bien escaso en la Alcarria, fue durante los siglos bajomedievales un elemento de gran importancia económica y símbolo de prestigio social, que despertó el interés de todos los grupos de la sociedad arriacense.
\end{abstract}

Palabras clave: agua, Baja Edad Media, Guadalajara, Castilla, infraestructura.

\begin{abstract}
One of the most critical elements for urban development in medieval Castile was access to water resources that could be used to supply human settlements. Depending on the climatic conditions, the surrounding terrain and previously existing infrastructures, each city and town in the kingdom sought the best means to secure a water supply for its population. In this article, we will analyse how the council of Guadalajara, together with the main religious and civil powers in the city, began to construct the local water supply network in the Late Middle Ages, fed by springs located in a place known as El Sotillo, and the start of commercial exploitation of the Henares River nearby the city. Water, a scarce resource in the Alcarria region, was of critical importance for the economy in the Late Middle Ages, as well as being a symbol of social prestige, and aroused the interest of all members of the local society.
\end{abstract}

Key Words: Water, Guadalajara, Late Middle Age, Castile, infrastructures.

${ }^{1}$ UNED Doctoral School (History, Art History and Territory programme). 
Sumario: 1. El agua en la Edad Media castellana. 2. El urbanismo en Guadalajara. El problema de las fuentes. 3. El medio físico y la morfología urbana. 4. La red de abastecimiento de agua. 5. La traída de aguas del Sotillo al palacio del Infantado de 1496. 6. Los gastos de construcción y mantenimiento de la infraestructura relacionada con el agua. 7. El río Henares. 8. Conclusiones. 9. Bibliografía

\section{EL AGUA EN LA EDAD MEDIA CASTELLANA}

El agua ha sido secularmente un elemento escaso en gran parte de Península Ibérica, y muy especialmente en las tierras de la Meseta. Por ello, el suministro de la misma ha supuesto un reto constante en el urbanismo hispano, siendo vital para la fundación de las ciudades en todas las épocas históricas la elección de enclaves donde la cercanía a cauces continuos de agua fuera compatible con la fácil defensa de las mismas. Durante la Baja Edad Media, y muy especialmente durante el siglo XV, el crecimiento urbano experimentado por la Corona de Castilla puso a prueba las infraestructuras hidráulicas de las villas y ciudades del reino, que en algunos casos eran heredadas de época romana o musulmana. Para afrontar las necesidades de abastecimiento de la población, los concejos castellanos trataron de buscar soluciones de diversa índole de forma que se pudiera aprovechar al máximo la disponibilidad de recursos, a la vez que intentaron poner en marcha nuevos sistemas de abastecimiento que permitieran a sus municipios seguir creciendo ${ }^{2}$.

Nuestro objetivo es realizar aportaciones novedosas que contribuyan a mejorar el conocimiento existente acerca del abastecimiento de agua en el urbanismo medieval castellano mostrando el ejemplo concreto de la ciudad de Guadalajara en los siglos XIV y XV y haciendo hincapié, de igual forma, en el papel que jugó el río Henares en la vida cotidiana de los habitantes del alfoz de la ciudad. Guadalajara, un municipio de tamaño medio ubicado en el centro de la península, puede ser un excelente ejemplo de cómo los concejos castellanos hacían frente a las necesidades de agua de sus vecinos, y de cómo los diversos grupos sociales pugnaron por lograr un mayor control de este recurso escaso, que en el caso alcarreño se convirtió también en un símbolo de estatus para la nobleza afincada en la ciudad.

${ }^{2}$ El estudio de los sistemas de captación y uso de agua es una línea de investigación con gran potencial, pues todavía son muchos los aspectos que desconocemos sobre este tema, y en ese sentido se enmarcan proyectos como el grupo de investigación de la Universidad de Valladolid, "Agua, Espacio y Sociedad en la Edad Media" (http://www3.uva.es/giragua/), así como diversos estudios realizados por varios autores para la corona castellana, que demuestran que éste es un campo de interés para la historiografía actual. Sin pretender ser exhaustivos, debido a las limitaciones de espacio de este artículo, podemos mencionar varias obras de investigación que nos han parecido especialmente relevantes, como Val Valdivieso y Bonachía Hernando, Agua y sociedad en la Edad Media Hispana; VAl Valdivieso, Usos sociales del agua en las ciudades hispánicas de la Edad Media; Val Valdivieso y Villanueva Zubizarreta, Musulmanes y cristianos frente al agua en las ciudades medievales; VAL VALDIVIESO, Agua y poder en la Castilla bajomedieval. El papel del agua en el ejercicio del poder concejil a fines de la Edad Media; JimÉnez AlCÁzAR, Agua y poder en Lorca durante la Baja Edad Media; Segura Graíño, "El abastecimiento de agua en Almería a fines de la Edad Media", pp. 1005-1017; Segura Graí̃̃o, Agua y sistemas hidráulicos en la Edad Media hispana; Parejo Delgado, "El abastecimiento urbano en Baeza y Úbeda en la Baja Edad Media" pp. 813-836; BARraGán MuÑoz, Agua, ciudad y territorio: aproximación geo-histórica al abastecimiento de agua a Cádiz; GARCÍA JiMÉNEz, Crónicas del agua. La importancia del agua en nuestra cultura; OLIVA HerRer, "L'eau et le pouvoir dans les villes castillanes à la fin du Moyen Âge. Palencia, un exemple de concurrence de pouvoirs", pp. 59-75. 


\section{EL URBANISMO EN GUADALAJARA. ELPROBLEMA DE LAS FUENTES}

La historia de Guadalajara en la Edad Media es, todavía, una gran desconocida, especialmente en lo que respecta a los aspectos urbanísticos. La escasez de fuentes documentales referentes a los siglos medievales, así como de edificios anteriores al siglo XV han sido escollos muy importantes que han provocado que la historiografía local se haya centrado en otras épocas, como el siglo XVI, para las que existen fuentes mucho más abundantes ${ }^{3}$. Los pocos estudios dedicados al periodo medieval tras la conquista cristiana han tenido por lo general que establecer sus hipótesis a partir de la documentación conservada de las últimas décadas del siglo XV, cuando las series documentales del Archivo Municipal de Guadalajara comienzan a tener un volumen y continuidad en el tiempo aceptables ${ }^{4}$. Debido a este motivo, muchas cuestiones que afectan a la morfología urbana de la capital alcarreña, así como al estudio de la vida cotidiana de sus vecinos antes de la segunda mitad del siglo XV deben ser enfocados en muchos casos desde el terreno de las hipótesis, que deberán ser confirmadas o desmentidas en la medida de lo posible por la arqueología, que hasta el momento apenas ha tenido ocasión de demostrar su potencial en Guadalajara, en gran parte debido a la destrucción sistemática a la que ha sido sometido el patrimonio histórico arriacense durante el siglo $\mathrm{XX}^{5}$.

Además del Archivo Municipal, ha sido posible encontrar fuentes primarias relevantes en varios archivos nacionales, si bien en muchos casos se trata de documentos aislados que arrojan información muy fragmentada sobre el tema objeto de estudio. En ese sentido, además de algún documento que cita ciertos aspectos urbanísticos de la ciudad que hemos podido hallar en el Registro General del Sello del Archivo General de Simancas, creemos relevante citar ciertas referencias identificadas en el fondo de Osuna de la Sección Nobleza del Archivo Histórico Nacional, donde se conserva documentación de los poderosos Mendoza alcarreños, cuya influencia en la ciudad ha quedado cristalizada en las fuentes documentales que generaron o guardaron en sus propios archivos privados. También conservamos en el Archivo Histórico Nacional algunos documentos relativos a varios de los conventos y monasterios de Guadalajara, cuyo impacto en el urbanismo local ha quedado en ocasiones reflejado en las fuentes. Finalmente, podemos mencionar dos dibujos de la ciudad muy interesantes, que nos permiten conocer su morfología durante el Antiguo Régimen, como son los

${ }^{3}$ Es preciso destacar la monumental obra de Layna Serrano sobre la historia de Guadalajara y la familia Mendoza en los siglos XV y XVI como la principal referencia bibliográfica para cualquier investigación sobre la ciudad en la Baja Edad Media. En los cuatro volúmenes que componen su investigación, el autor aporta valiosa información tanto sobre la vida de los principales miembros del linaje alcarreño, como de la sociedad, política, cultura y economía locales en los siglos de mayor esplendor del municipio (LAYNa SERRANo, Historia de Guadalajara y sus Mendozas en los siglos XV y XVI).

${ }^{4}$ En ese sentido es imprescindible la consulta de LÓPEZ VILLALBA, Las actas de sesiones del concejo medieval de Guadalajara; LóPez Villalba, Fuentes históricas de Guadalajara. Archivo Municipal de Guadalajara, II; LuIs LóPEZ, Fuentes históricas de Guadalajara. Archivo Municipal de Guadalajara, III; LuIs LóPEZ, Fuentes históricas de Guadalajara. Archivo Municipal de Guadalajara, IV.

${ }^{5}$ De forma ilustrativa, debemos destacar las excavaciones en el antiguo alcázar de la ciudad así como los trabajos de Cuadrado Prieto, Arenas Esteban y Crespo Cano, "Estudio preliminar de la secuencia estructural del Alcázar de Guadalajara", pp. 279-298,y los de Pavon Maldonado, Guadalajara medieval: arte y arqueología árabe y mudéjar. 
realizados por Wyngaerde en 1565 y por Baldi en 1668, que nos ayudan visualmente a realizar ciertas interpretaciones sobre cómo era Guadalajara en la Edad Media.

Por lo tanto, se ha realizado el estudio a partir de las fuentes documentales y arqueológicas existentes sobre el entramado urbano de Guadalajara, con el soporte de los trabajos realizados hasta ahora sobre su morfología, entre los que debemos destacar los de Pradillo Esteban ${ }^{6}$. Con todos estos recursos, trataremos de aportar más información acerca de la importancia que el agua tuvo en el desarrollo y crecimiento de esta ciudad a orillas del río Henares.

\section{EL MEDIO FÍSICO Y LA MORFOLOGÍA URBANA}

La ciudad de Guadalajara está situada en el Noroeste de la submeseta Sur española. Debido a la lejanía del mar soporta un clima continental con precipitaciones escasas, concentradas sobre todo en otoño y primavera, así como fuertes oscilaciones de temperaturas tanto diarias como estacionales ${ }^{7}$. El agua, por tanto, es un recurso escaso cuyo suministro ha requerido la atención de los pobladores de la ciudad ya desde época de dominación musulmana.

La localización de Guadalajara obedece a razones defensivas, pues se ubica en una loma sobre el río Henares protegida por dos barrancos que la encorsetan a Este (el barranco del Alamín) y a Oeste (el de San Antonio). Estas estrechas torrenteras, que servían de foso natural a las murallas del municipio, se van aproximando paulatinamente entre sí según avanzan hacia el Norte, de forma que cuando desembocan en el Henares forman un estrecho paso que permite subir desde el río, aprovechando un vado, hacia la meseta alcarreña. Este espacio aproximadamente triangular que se va abriendo de Norte a Sur era un enclave de gran importancia, pues permite vigilar el río desde un lugar de fácil defensa. La conveniencia de controlar este lugar ha provocado que estuviera habitado ya desde época romana, pues existen indicios de la existencia de un poblamiento cercano llamado Arriaca, sobre cuya ubicación exacta conviven varias teorías, y que pudiera considerarse el origen de la actual Guadalajara.

Dejando de lado las dudas acerca de la localización exacta de la antigua Arriaca, podemos asegurar que el núcleo original de la Guadalajara actual fue edificado bajo dominación musulmana, a partir de un pequeño recinto amurallado culminado por un alcázar que aseguraba el control militar de esta zona estratégica bajo influencia de Toledo ${ }^{8}$. A partir de la conquista cristiana de la villa, este espacio urbano se fue desplazando y creciendo hacia el Sur, alejándose del río Henares para aprovechar una orografía del terreno más cómoda, formando el definitivo recinto amurallado que caracterizará a la ciudad durante los siglos bajomedievales y toda la Edad Moderna.

El río Henares es el eje que vertebra el territorio sobre el que se asienta la ciudad, cuya zona de influencia parte en dos mitades: al Oeste se abre la comarca de la Campiña, que es un territorio de orografía suave muy indicado para la agricultura. Al Este, el río Henares ha dejado una serie de terrazas fluviales que crean un perfil del terreno

\footnotetext{
${ }^{6}$ Pradillo Estéban, “Organización del espacio urbano en la Guadalajara medieval”, pp. 215-246.

7 VV.AA., Auditoría de sostenibilidad del municipio de Guadalajara, p. 36.

${ }^{8}$ Pavon Maldonado, Guadalajara medieval: arte y arqueología árabe y mudéjar.
} 
mucho más escarpado que sirve de transición hacia la meseta del páramo alcarreño, la cual se eleva unos 200 metros por encima de la altitud de la ciudad. Guadalajara se ubica, por tanto, en un espacio elevado sobre el Henares, y por debajo de la meseta alcarreña, en una zona de transición marcada por la presencia de una sucesión de barrancos que drenan el agua de lluvia hacia el río y que forman una serie de lomas como aquella en la que se ubica la ciudad.

Ambos elementos, el páramo de la Alcarria y el río Henares, son los que definen el mapa del agua alrededor de Guadalajara. La importancia del Henares radica en que es el único cauce continuo de agua del que goza la ciudad de Guadalajara, pues los barrancos antes mencionados, entre los que incluimos el del Alamín y el de San Antonio, que bordean la muralla arriacense, siempre fueron cauces intermitentes que vertían el agua de lluvia al río Henares solo en los días de mayores precipitaciones, y por tanto no pudieron ser nunca tenidos en cuenta para el abastecimiento humano. La importancia del río para los vecinos de la ciudad y los pueblos cercanos se evidencia en la documentación existente, que muestra usos agrícolas en su vega, actividad pesquera, así como diversas disputas por el acceso a sus aguas por parte de los ganaderos de la zona.

El segundo elemento definitorio del paisaje de la ciudad a efectos de este estudio es el páramo alcarreño, denominado históricamente como el monte Alcarria. Su composición geológica es muy interesante, pues al predominar los materiales calizos ${ }^{9}$, el agua de lluvia se filtra al subsuelo manando posteriormente en forma de fuentes a lo largo de todo el reborde de la meseta, las cuales han aportado el agua necesaria para muchos de los pueblos del entorno, así como a la propia ciudad de Guadalajara, que se ha beneficiado de estas fuentes hasta el siglo XX, cuando se construyó el sistema actual de abastecimiento desde el río Sorbe ${ }^{10}$. La localización de estos manantiales no es sencilla, pero ateniéndonos a la documentación de archivo estudiada, podemos conocer la situación de las más relevantes, lo que permite mostrar la figura $1^{11}$, que ha sido elaborada a partir de un mapa satélite de la ciudad y sus alrededores ${ }^{12}$. La imagen no refleja todas las fuentes halladas en los documentos, sino solo aquellas para las cuales contamos con referencias territoriales y toponímicas suficientes como para ubicarlas en un mapa de forma aproximada con ciertas garantías, pero en cualquier caso sirve para ilustrar perfectamente las dos formas de suministro de agua en Guadalajara: el río Henares, y los manantiales de la cornisa de la meseta alcarreña:

\footnotetext{
9 BlázQuez, Mapa hidrológico de la provincia de Guadalajara, p. 3.

${ }^{10}$ VV.AA., Auditoría de sostenibilidad del municipio de Guadalajara, p. 259.

11 La ubicación de las fuentes se ha podido situar aproximadamente en el mapa gracias a las referencias encontradas en el documento: Archivo Municipal de Guadalajara (en adelante AMGU), 133139.

12 Obtenido en la página web del Instituto Geográfico Nacional (www.ign.es/iberpix2/visor)
} 


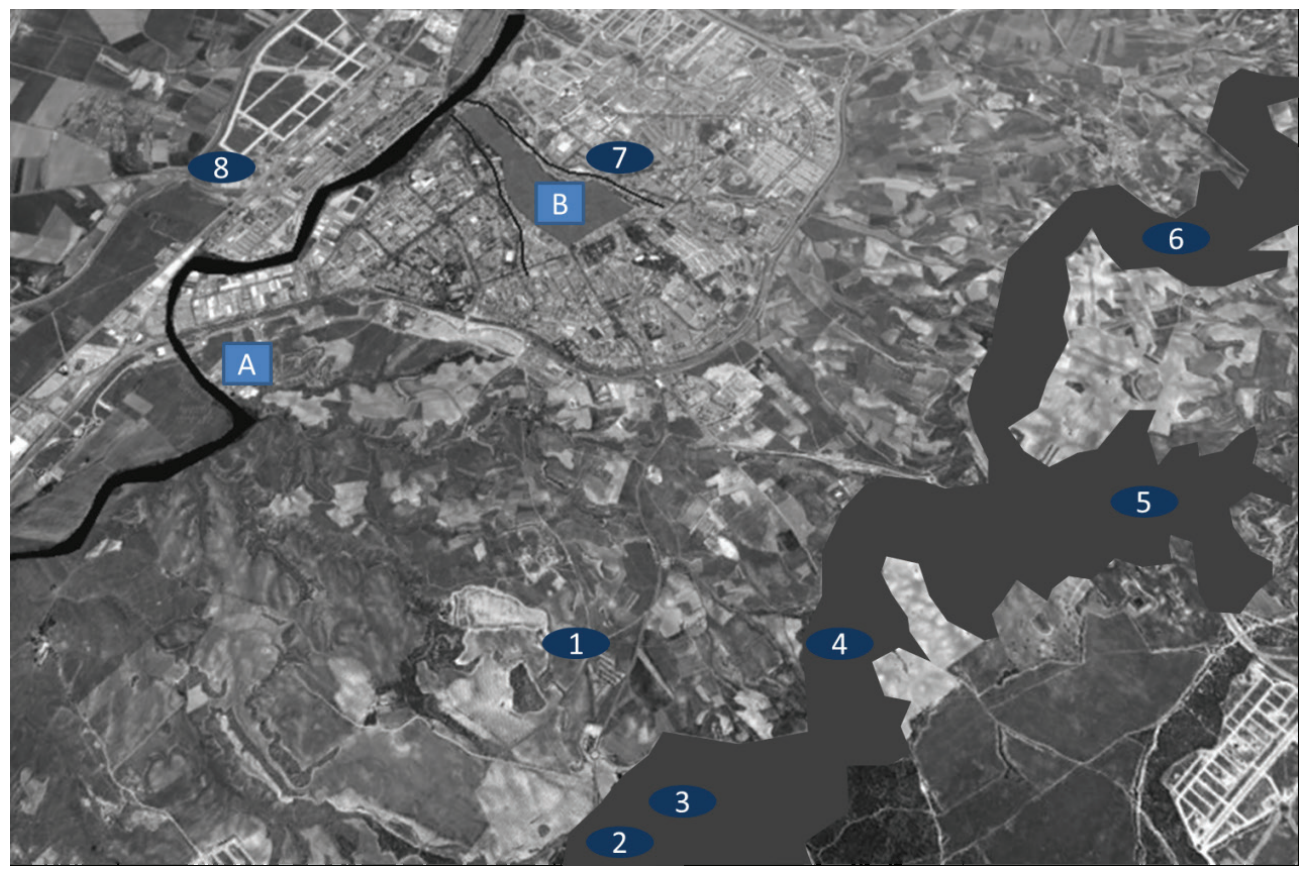

Fig. 1. Recursos hídricos de la ciudad de Guadalajara, mostrados sobre una foto satélite de la ciudad en la actualidad: A) Río Henares; B) Perímetro amurallado de la ciudad, con los barrancos de San Antonio (Oeste) y Alamín (Este); 1) Fuente de Valdeapa; 2) Fuente de Alzucema; 3) Fuente de Ceclavín; 4) Fuente de Zurraque; 5) Fuentes del Sotillo; 6) Fuente de Iriépal; 7) Fuente del Alamín; 8) Fuente del Camino de Cabanillas. En sombreado, al Sureste de la ciudad se refleja el reborde de la meseta alcarreña.

Finalmente, para completar el mapa de recursos hídricos del entorno de la ciudad, debemos mencionar la disponibilidad de agua subterránea, que se encuentra con cierta facilidad en la zona. La presencia de pozos en viviendas particulares está documentada desde época musulmana, según se ha podido comprobar en las excavaciones arqueológicas realizadas en el casco antiguo arriacense, entre las que debemos destacar a modo de ejemplo las realizadas con motivo de las obras del túnel de Aguas Vivas $^{13}$, donde se han encontrado antiguos pozos, que nos hacen suponer que este tipo de recursos fueron utilizados de forma habitual para el uso doméstico. En esa línea, la ausencia de referencias a los pozos en los documentos conservados invita a pensar que éstos se utilizarían casi exclusivamente en la esfera privada, posiblemente en los patios interiores de las viviendas, pues no existe noticia de que el concejo tuviera algún interés público en los mismos.

${ }^{13}$ Serrano Bertos, Torra Pérez, Castro Priego y Sánchez González, "Excavaciones en Guadalajara: secuencia andalusí desde época emiral a taifa y presentación de un singular conjunto numismático", pp. 79-114. 


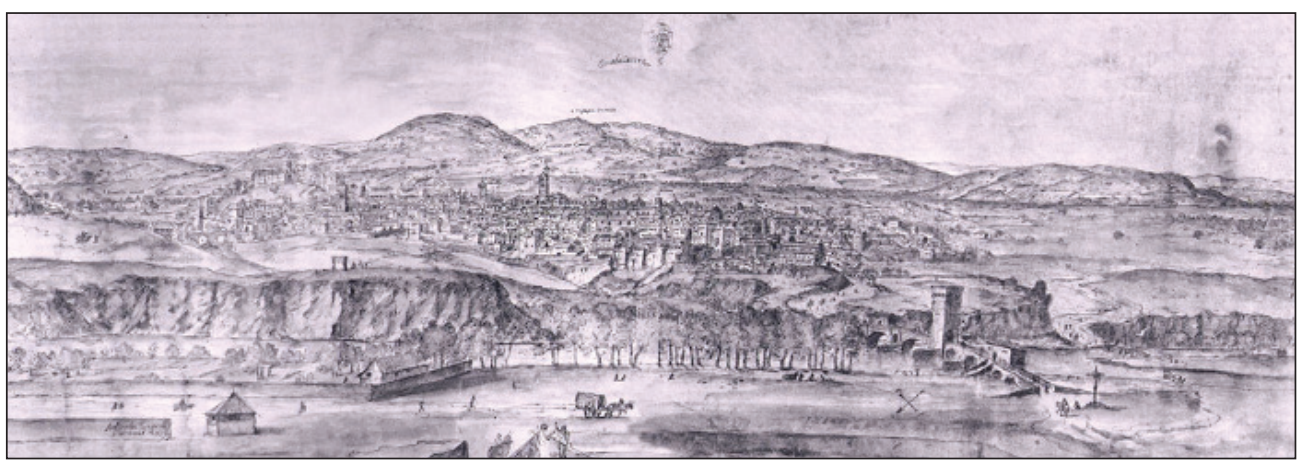

Fig. 2. Ilustración de la ciudad de Guadalajara realizada en 1565 por Anton Van der Wyngaerde. Esta imagen refleja a la perfección la morfología de la ciudad al final de la Edad Media. El río Henares queda en primer plano, con su puente fortificado, tras el cual se observa la loma en la que se asienta la ciudad, flanqueada por los barrancos del Alamín, a la izquierda de la imagen, y de San Antonio, a la derecha. El recinto amurallado queda muy elevado sobre el río, del que le separa un espacio casi deshabitado, que corresponde con el arrabal de la Alcallería, antiguo centro de la ciudad musulmana. Tras las murallas, se observa al fondo el monte Alcarria, origen de la mayoría de fuentes que abastecían a la ciudad.

Fuente: http://enwada.es/w/images/Vista_Guadalajara_1565.jpg.

\section{LA RED DE ABASTECIMIENTO DE AGUA}

Se desconoce cuándo se comenzó a construir la red de abastecimiento local de agua de Guadalajara, si bien el cronista Diges Antón opinaba que el origen de las canalizaciones subterráneas en la ciudad se remontaría a época califal ${ }^{14}$. No es posible confirmar o desmentir esa hipótesis con la información de que disponemos, aunque es cierto que las fuentes musulmanas del siglo $\mathrm{X}$, en sus escasas referencias a Guadalajara, la describen como un enclave con abundancia de agua y lugares para el baño, para lo que bien pudiera ser que se estuviera haciendo uso de los manantiales cercanos ya en aquel momento ${ }^{15}$.

La fuente documental más antigua que hemos encontrado acerca del suministro de agua data de principios del siglo XIV, y es la que debemos utilizar como punto de partida para comprender el funcionamiento del sistema de abastecimiento urbano. El texto se conoce de manera indirecta gracias a una cédula firmada por la reina Juana en 1534 donde se inserta su traslado. Es una confirmación de un privilegio fechado en 1309 por medio del cual las monjas del monasterio de Santa Clara, intramuros de la ciudad, adquirían derecho de uso de cierto caudal de agua, otorgado por el concejo arriacense ${ }^{16}$.

14 Diges Antón, Guía del turista en Guadalajara, pp. 114-116.

15 SerranoBertos, Torra Pérez,CastroPriegoySánchezGonzález, “ExcavacionesenGuadalajara:secuencia andalusí desde época emiral a taifa y presentación de un singular conjunto numismático", pp. 79-114.

16 Archivo Histórico Nacional, Sección Nobleza (en adelante AHN-SN), OSUNA, C.1879, D.3. 
En el documento se describe el trazado principal de las canalizaciones urbanas en aquel momento, que partían de las cercanías de la entonces villa, posiblemente desde la fuente del Sotillo, hasta las proximidades del monasterio de San Francisco, situado extramuros muy cerca de la puerta de Bejanque. Desde ese punto, donde los frailes tomaban la cantidad que necesitaban, el agua se canalizaba hacia la fuente de Santa María, y desde allí se dividía a partes iguales entre el Alcázar Real, la fuente de la iglesia de San Andrés, y el convento de Santa Clara. El sistema era muy sencillo, de estructura casi lineal, y aprovechaba la pendiente existente entre la fuente del Sotillo y el río Henares, de forma que por gravedad el agua pasaba de un punto de consumo al siguiente. Su estructura permitía la existencia de dos fuentes públicas, la de Santa María y la de San Andrés. La primera de ellas evolucionaría hasta ser uno de los ejes vertebradores de la vida local, siendo un espacio de encuentro entre los vecinos, pues a la fuente se sumaba la presencia de varios comercios locales y la iglesia de Santa María, lo que hacía de la plaza el lugar indicado para celebraciones y eventos religiosos. Respecto a los espacios privados abastecidos, el suministro de agua cubría las necesidades de los dos monasterios principales de Guadalajara: San Francisco y Santa Clara, así como del alcázar, cuya importancia defensiva era vital para la entonces villa.

Es interesante comprobar que el sistema anterior no suministraba agua a ningún palacio en la ciudad, posiblemente por la ausencia de un poder nobiliario fuerte que pudiera sufragar los costes de tal infraestructura. Esto cambió con la llegada a la ciudad en el siglo XIV de la familia Mendoza, que comenzaría su imparable ascenso social a partir de su posición de poder en Guadalajara. El crecimiento en prestigio y riqueza de los Mendoza fue paralelo a la necesidad de ostentación de lujo de sus miembros, y en ese sentido Pedro González de Mendoza, mayordomo mayor de Juan I, decidió construir las casas mayores de la familia donde hoy se ubica el suntuoso palacio del Infantado. El diseño del edificio, de cuyo aspecto físico no se conserva noticia alguna, contemplaba un suministro de agua corriente, para lo cual el Mendoza pidió al concejo de la villa que le donara parte del agua de la red de abastecimiento existente. El concejo, dominado por la red clientelar del magnate, le concedió en 1376 un caño de agua "para vuestras casas mayores que vos agora fecistes ${ }^{17 "}$ ", que sería realizado en hierro, con un diámetro "como un cornado ${ }^{18 "}$ ". El sobrante de este volumen de agua fluiría posteriormente hacia el cercano palacio de la duquesa de Arjona, donde hoy está situada la iglesia de los Remedios, a escasos metros de distancia. Tras incorporar los dos palacios más importantes de la nobleza de la ciudad, el circuito de canalización de agua potable debió funcionar sin variaciones de importancia a lo largo de gran parte del siglo XV.

En el siglo XV, y especialmente desde el reinado de Enrique IV, la ciudad creció significativamente, a la par que aumentaba el prestigio y riqueza de la familia Mendoza, verdaderos señores de hecho, si bien nunca de derecho, de la ciudad ${ }^{19}$. Así, el

\footnotetext{
${ }^{17}$ Layna Serrano, El palacio del Infantado en Guadalajara, p. 15.

${ }^{18}$ Layna Serrano, Historia de Guadalajara y sus Mendozas en los siglos XV y XVI, II,p. 403.

${ }^{19}$ Consideramos muy ilustrativo realizar una somera enumeración de las rentas y privilegios más importantes de los Mendoza en la Tierra de Guadalajara a finales de la Edad Media, que demuestran su poder sobre la ciudad: el cabeza de la familia tenía la costumbre de nombrar, mediante un procedimiento indirecto, las
} 
poderoso clan dirigido por el marqués de Santillana, y posteriormente por sus hijos, entre los que destacan personalidades como el Cardenal Mendoza, el I duque del Infantado, o el I conde de Tendilla, formaron una creciente corte local bajo cuya protección fueron llegando muchas familias a la capital alcarreña, destacando entre ellas hidalgos procedentes de los señoríos mendocinos del Norte del reino, que provocaron un fuerte incremento de la población local, y por tanto del consumo de agua, que se fue convirtiendo en un bien cada vez más escaso, pues el caudal de los manantiales utilizados era muy limitado, y sujeto al irregular régimen de lluvias que caracteriza al clima de la comarca.

Esta escasez se puede observar ya en la disputa mantenida en 1420 por Íñigo López de Mendoza, en aquel momento señor de Buitrago y futuro marqués de Santillana contra su hermana la duquesa de Arjona y su marido, el conde don Fadrique. El conflicto se inició cuando el Mendoza comenzó a impedir que el agua fluyera desde su palacio al de los condes, provocando un conflicto entre las clientelas de unos y otros, que había degenerado en "bolliçios e escándalos", que el propio monarca, Juan II, se vio obligado a controlar para asegurar la convivencia en la ciudad, mandando a un juez a investigar los hechos y apaciguar los ánimos ${ }^{20}$. Posiblemente la decisión del marqués de acaparar todo el agua que llegaba a su palacio se debiera a que el consumo en la fuente de Santa María, aguas arriba en el sistema de canalización, hubiera crecido debido al incremento demográfico del municipio, si bien no podemos descartar una acción malintencionada debida a disputas entre ambas familias por motivos de herencias. En cualquier caso, esta situación dibuja un escenario en el que el agua se concibe como un bien escaso.

La necesidad de aumentar el caudal de agua que llegaba a la ciudad fue paliada en parte hacia 1450 gracias a Isabel de Vera, viuda de Íñigo López de Mendoza, señor de Rello ${ }^{21}$, quien decidió donar al convento de San Francisco el agua de todas las fuentes que poseía en el Sotillo ${ }^{22}$. Como hemos indicado, los frailes de San Francisco eran los primeros consumidores de agua en el sistema lineal de canalización que llegaba a Guadalajara, por lo que el incremento del caudal recibido beneficiaba al resto de edificios que contaban con agua corriente, así como a las fuentes públicas.

El documento de la donación de Isabel de Vera nos permite conocer un poco mejor como era el suministro del Sotillo, pues explica que éste se componía de varias fuentes, algunas de las cuales eran propiedad del concejo, mientras que otras formaban parte del patrimonio de diversos miembros de la familia Mendoza. Isabel de Vera menciona la "fuente mayor que yo tengo en posesión e me pertenesçe (...) que es la mayor de todas las que yo he e tengo e me pertenesçen en el dicho Sotillo", así como

personas que debían ocupar los oficios municipales, privilegio que se sumaba a la tenencia del alcázar de la ciudad, el mantenimiento de un número importante de caballeros apaniaguados (SÁNCHEz León, Absolutismo y comunidad. Los orígenes sociales de la guerra de los comuneros de Castilla, p. 105), el control de la escribanía pública, las rentas de la martiniega, el pecho de San Miguel, el portazgo, la cabeza de pecho de moros, el servicio de montazgo, varios tipos de penas y caloñas, yantar y baño, además de las rentas de sus propiedades en el alfoz alcarreño, que ascendían a unas 1.300 fanegas de trigo y 1.500 de cebada (SÁNCHEZ Prieto, La casa de Mendoza hasta el tercer duque del Infantado (1350-1531), p. 341).

${ }^{20}$ AHN-SN, OSUNA, C. 1879 D.9.

${ }^{21}$ LaYna Serrano, Los conventos antiguos de Guadalajara, p. 105.

${ }^{22}$ AHN-SN, OSUNA, C. 1879, D.6. 
"el agua de todas las otras fuentes pequeñas que son en el dicho Sotillo". Gracias a esta donación, en línea con otras ofrecidas por los Mendoza a la comunidad de frailes, el monasterio de San Francisco adquiría unos derechos de agua considerables, si bien la citada Isabel de Vera ponía dos condiciones en su documento. La primera de ellas era que el transporte del agua quedaba bajo la responsabilidad de los monjes, que se deberían hacer cargo de los costes de la obra, y la segunda que ella pudiese aprovechar ese mismo agua para sus propias necesidades, lo que refuerza la idea de que este nuevo caudal se sumaría al ya existente fluyendo por el mismo conducto, de forma que aumentaría el caudal total de la red de abastecimiento antigua.

Bien fuera porque los frailes de San Francisco no habían ejecutado la obra, o bien porque las necesidades de agua de la ciudad seguían excediendo lo que las canalizaciones permitían, en 1454 el marqués de Santillana decide plantear al concejo de la ciudad realizar una inversión conjunta para captar y traer mayor cantidad de agua del Sotillo, construyendo una nueva fuente en la ciudad, bien en la plaza de San Gil, en la plaza Mayor, "o donde la villa deputase e ordenase" quedando el agua no consumida para su palacio. De este modo, el marqués propone que todos los estamentos de Guadalajara, incluidos los caballeros, contribuyesen al gasto necesario para la obra, ofreciendo él mismo su compromiso de que ordenaría a los vasallos que tenía en los municipios cercanos a que contribuyeran en su construcción.

El concejo recibió la propuesta del marqués con agrado, como no podía ser de otra forma considerando el poder e influencia del magnate sobre los ediles, y ordenó crear una comisión formada entre otros por los regidores de la villa, los "cuatro" o representantes del Común y varios maestros competentes en la materia, que se reunirían con el marqués para analizar las posibilidades de ejecución del proyecto ${ }^{23}$.

La idea debió ser desestimada, pues no hay constancia documental acerca de obras hidráulicas que pudieran ser asociadas con ella, ni tampoco se conoce la existencia de una fuente en San Gil ni en la plaza Mayor en estos años. Es probable que la idea de 1454 fracasase porque el gasto de la construcción de la infraestructura para canalizar el agua debía ser sufragado en parte por un concejo cuyas rentas de propios eran escasas, lo que obligaba a realizar repartimientos adicionales de impuestos que sin duda encontrarían la resistencia a contribuir por parte de los pecheros.

A pesar de esto, los Mendoza, cada vez más dueños de la ciudad, seguían codiciando obtener más agua del Sotillo, y en 1474 vuelven a negociar con los regidores de Guadalajara para tratar de conseguir el caudal que necesitaban para su palacio. En esta ocasión es el hijo del marqués de Santillana, el I duque del Infantado, el que realiza las gestiones con la ciudad, adoptando una estrategia diferente a la empleada por su padre veinte años antes. Así, conocedor de la escasa capacidad financiera del concejo, consigue que éste le done varias fuentes del Sotillo que eran de propiedad pública, para poder traer el agua a su costa a su palacio. En este caso el futuro proyecto de canalización ya no dependía de un poder público, sino exclusivamente de la iniciativa privada, lo que suponía el golpe definitivo al control de un recurso comunal

${ }^{23}$ AMGU, 1H 0084A, Libro de actas de sesiones del concejo (en adelante LA), 1454, f. 10v. Edit.: LóPEZ VILlalba, Las actas de sesiones del concejo medieval de Guadalajara, p. 63. 
por parte de la poderosa familia Mendoza, pues perdía su condición de bien de uso libre y gratuito para los vecinos ${ }^{24}$.

La donación de 1474 fue confirmada al nieto del marqués, el II duque del Infantado, en 1491, fecha en la que el concejo entregó al Mendoza el agua de ciertas fuentes del Sotillo ${ }^{25}$, quizá las mismas que se habían entregado a su padre, o bien otras nuevas recién alumbradas que complementaban a las anteriores, de manera que

La dicha agua la pueda mandar traher a esta dicha çibdad a las dichas sus casas e a donde su señoría quisierede e por bien tovierede e la pueda tener e fazer della lo que quisierede e por bien tovierede para sienpre syn que esta dicha çibdad nin por persona alguna en su nonbre agora nin en algund tiempo sea perturbada.

Una vez controlada el agua del Sotillo que poseía el concejo, y en vista de que el caudal obtenido no era suficiente para ampliar la red de abastecimiento, los miembros de la susodicha familia Mendoza pusieron su vista en otros manantiales cercanos de menor importancia, como eran los de Zurraque y Ceclavín, ambos localizados en las cercanías de la actual urbanización del Clavín, muy próxima a Guadalajara, y situada en el reborde del páramo alcarreño, al igual que el Sotillo, del que distan apenas unos centenares de metros en línea recta. En 1492 otro Mendoza, en este caso el conde de Coruña, quizá movido por la necesidad de competir en ostentación con el duque del Infantado, decide suministrar agua corriente a su palacio, situado intramuros de Guadalajara, para lo cual pidió al concejo la mitad del agua de ambos manantiales, comprometiéndose a canalizarla hasta la ciudad pagando el coste a partes iguales con el concejo. Según esta propuesta, la mitad del agua quedaría a disposición de los vecinos en una fuente pública que se construiría en las cercanías de la ermita del arrabal de Santa Catalina, mientras que el resto serviría para abastecer su palacio. Los regidores accedieron a realizar la donación de ambas fuentes en los términos pedidos por el conde, $\mathrm{y}$ en la misma sesión del ayuntamiento, a la que acudieron también los pecheros de la ciudad, se acordó entregar al duque del Infantado toda el agua sobrante que manara de la fuente de Santa María, para que la pudiera llevar a su palacio, o a donde él quisiera ${ }^{26}$. Posiblemente esta última concesión al duque sería algún tipo de contrapartida solicitada por éste a cambio de permitir que el concejo hiciera la donación al conde de Coruña.

Apenas unos meses después de esta donación, en el mismo año de 1492, los Reyes Católicos concedieron al Cardenal Mendoza el agua de esas mismas dos fuentes de Zurraque y Ceclavín ${ }^{27}$ para que

Podades traer el agua de la dichas fuentes e de cada una dellas o de qualquier dellas por caños o en otra qualquier manera que vos quisieredes a la casa que tenedes del vuestro patrimonio en la dicha çibdad de Guadalajara o en otra parte o partes qualesquier que vos quisierdes e por bien tuvieres e partyrla e repartirla por los lugares e en la manera que vos paresçiere e bien visto vos fuere.

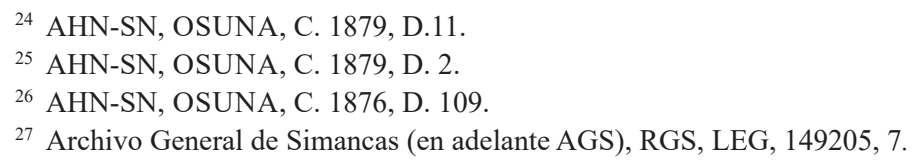


En la misma carta se concede al cardenal la potestad de llevar los caños por donde considerara oportuno, permitiéndole con tal fin levantar calles, caminos, plazas o tierras públicas por donde fuera necesario realizar las zanjas para canalizar el agua de las fuentes, siempre que devolviera todo a su estado original.

Es interesante advertir que mientras las fuentes del Sotillo habían sido una donación del concejo a los Mendoza, en el caso del poderoso cardenal son los monarcas los que deciden hacer uso de su patrimonio realengo para realizar una merced a uno de sus servidores más importantes, sin contar en esta ocasión con el visto bueno, o siquiera con la opinión del concejo alcarreño, que ese mismo año había donado el mismo recurso al conde de Coruña. Todo indica que desde la Corona no se comunicó tal hecho al concejo de Guadalajara, pues los regidores, estando reunidos el 3 de junio de 1492 en sesión ordinaria frente a la iglesia de Santo Domingo, recibieron la visita inesperada del mayordomo del cardenal, el cual les mostró la carta de donación de los monarcas, exhortándoles con ella a cumplir el mandato de los soberanos ${ }^{28}$.

No cabe duda de que la irrupción del sirviente del cardenal debió ser una sorpresa para los miembros del concejo, pues éstos no supieron darle una respuesta en aquel momento, y le emplazaron a una nueva sesión que se celebraría unos días más tarde, el 9 de junio. En la nueva convocatoria del ayuntamiento, el mayordomo del prelado vuelve a dirigirse al concejo en pleno para mostrar la misiva escrita por los monarcas a la ciudad exigiendo su cumplimiento ${ }^{29}$. En esta segunda ocasión, el concejo tenía la respuesta preparada, pues había analizado con calma la carta, y en ese sentido la ciudad contestó al sirviente del cardenal que estaban dispuestos a cumplir lo mandado por los reyes, pero que no podían ir contra la donación que había sido previamente hecha de las mismas fuentes al conde de Coruña. La lectura detenida del acta conservada de aquella sesión del concejo es muy interesante, pues muestra la asistencia aquel día de todo el concejo, pecheros incluidos, y es muy relevante la presencia en la sala como testigo de Juan Díaz, al que se describe como "criado del señor duque del Infantazgo". El asunto era familiar, sin duda alguna, y el duque, como cabeza del clan mendocino, no quería dejar de conocer el resultado de esta disputa por el agua de Guadalajara que afectaba a dos miembros destacados de su familia.

El mayordomo del cardenal pidió una copia de la respuesta del concejo, y abandonó la reunión para dar parte de lo acontecido a su señor, quien a buen seguro no recibiría las noticias con agrado. Por otro lado, y a pesar de haber conseguido el preciado recurso, el conde de Coruña acabó desestimando el proyecto, bien fuera por motivos financieros o bien porque el caudal aportado por ambas fuentes no fuera suficiente como para asegurar el suministro necesitado.

La red de abastecimiento de agua para consumo urbano se completaría a partir de la donación que el mismo año de 1492 hizo el II duque del Infantado al monasterio de San Antolín, situado extramuros en el arrabal de la Alcallería, el más próximo al Henares, al que le concedió toda el agua que originalmente debía abastecer al palacio de la duquesa de Arjona, hermana de su abuelo, el marqués de Santillana. Sin embargo, la donación parece que no se hizo efectiva por los menos hasta 1531, cuando el III duque confirmó la voluntad de su padre, y los frailes vendieron un censo anual

\footnotetext{
28 AHN-SN, OSUNA, C. 1876, D. 109.

29 AHN-SN, OSUNA, C. 1879, D. 13.
} 
de 13.244 maravedíes y dos gallinas para costear la obra. Es posible que ni siquiera entonces la comunidad monástica consiguiera el agua para su edificio, pues en aquel momento unos hijos del duque se habían quedado a vivir en el antiguo palacio, y reclamaban el agua para sí. Quizá por este motivo, en 1533 el IV duque, Íñigo López de Mendoza, decidió donar al monasterio un dedo de agua de su palacio del Infantado, para que lo llevaran a su costa allí donde lo necesitaran ${ }^{30}$.

Todo lo anterior nos permite conocer cómo era la red principal de abastecimiento de agua de la ciudad, que al final de la Edad Media quedaría dispuesta según se muestra en la figura 3, para cuya elaboración hemos considerado que las tuberías se habrían construido por las calles principales. Esta red hidráulica era complementada por otras canalizaciones de menor importancia, entre las que se encuentran simples desagües que llevaban el agua de lluvia extramuros de la ciudad hacia los dos barrancos que la flanquean, fuentes menores que manaban dentro del recinto amurallado, pozos privados ${ }^{31}$, o también conexiones secundarias que partían de la red principal que formaba el eje San Francisco-Santa María-Palacio del Infantado. En relación a estas canalizaciones menores, sabemos de la existencia al menos de unos baños cerca de la puerta de Alvar Fáñez, donados por Alfonso VIII a don Cerebruno, arzobispo de Toledo ${ }^{32}$. También destacamos el testamento de Brianda de Mendoza y Luna, fundadora del convento de la Piedad, datado en 1534, en el cual la aristócrata menciona la presencia de unos baños cerca del monasterio, cuyo abastecimiento sin duda debió requerir cierta infraestructura para traer el agua. También prohíbe que se realicen enterramientos dentro del convento, especialmente en los "corredores ni en el patio ni se desenlose porque como van por todo esto muchos caños e mynas y el agua del pozo a la guerta y las demás del patio e del patinico de la botillería a la privada para alinpialla ${ }^{33}$ ". Desconocemos la fecha en la que se construyeron los caños aludidos, ni el baño o "privada" mencionado, pero no es descartable que al menos parte de la infraestructura mencionada tuviera un origen incluso anterior al siglo XV, pues donde se alzó el convento era uno de los barrios más poblados de la ciudad, lugar de mayoría hebrea hasta su expulsión en 1492, donde la comunidad judía tenía sus baños ${ }^{34}$.

${ }^{30}$ Layna Serrano, Los conventos antiguos de Guadalajara, p. 34.

31 Al igual que en otras ciudades como Madrid, Murcia, Granada o Málaga, la existencia de agua subterránea permitía la creación de pequeños pozos que serían usados en el ámbito doméstico. Estos pozos solían ser un recurso hídrico muy utilizado en las ciudades pequeñas y medianas hispanas desde época andalusí. (JIMÉNEZ RAYADO, "El abastecimiento de agua en Madrid durante la Edad Media", pp. 241-273).

32 Hernández, Los cartularios de Toledo. Catálogo documental, p. 163.

33 Layna Serrano, Los conventos antiguos de Guadalajara, pp. 400 y ss.

34 GARcía LóPez, Historia de la muy nobilissima ciudad de Guadalaxara dedicada a su illustrissimo ayuntamiento por don Francisco de Torres, su regidor perpetuo, año de 1647,p. 27. 


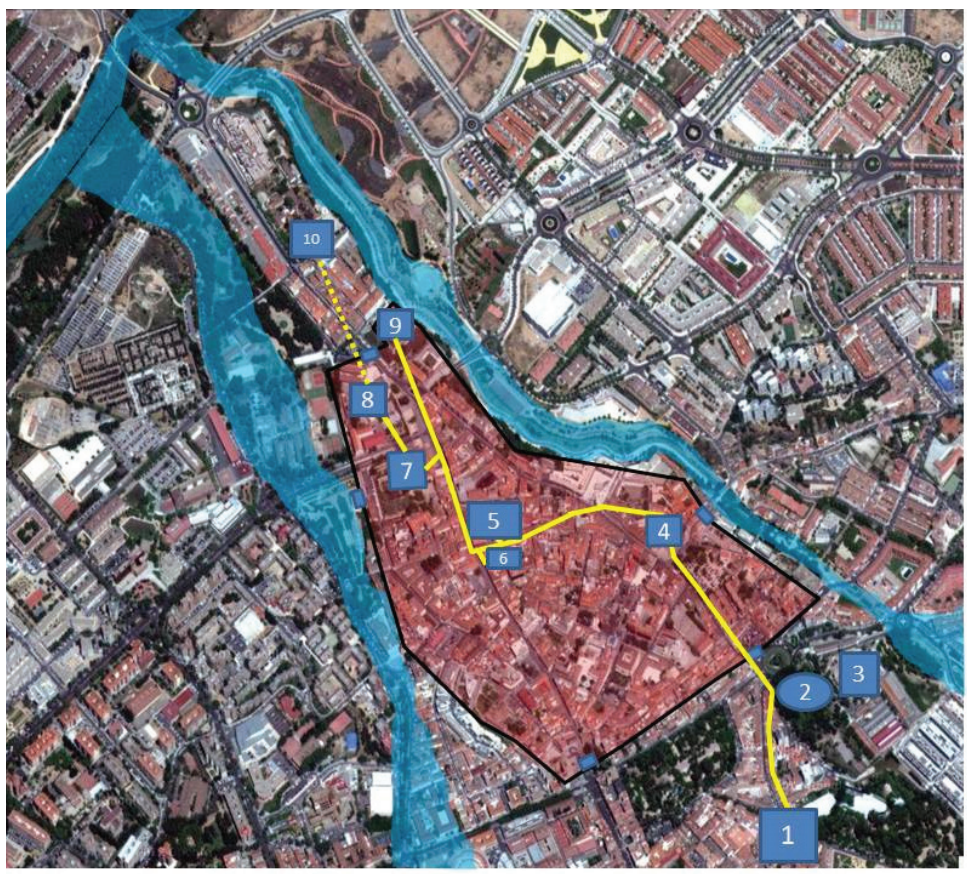

Fig. 3. Canalización de agua corriente en la ciudad de Guadalajara hacia 1500 (en línea negra de delimita el perímetro amurallado). 1) Viaje de agua del Sotillo; 2) Estanque de San Francisco o de Santa Ana; 3) Monasterio de San Francisco; 4) Santa María de la Fuente; 5) Convento de Santa Clara; 6) Fuente de la iglesia de San Andrés; 7) Palacio del Infantado; 8) Palacio de la duquesa de Arjona; 9) Alcázar Real; 10) Monasterio de San Antolín (en proyecto).

\section{LA TRAIDA DE AGUAS DEL SOTILlO AL PALACIO DEL INFANTADO DE 1496}

Explicábamos anteriormente que el agua del Sotillo había sido canalizada hasta las cercanías del monasterio de San Francisco al menos desde 1309. Esta canalización fue en sus inicios una construcción precaria, pues al no tener los frailes fondos suficientes para poner en pie una infraestructura de calidad, tuvieron que conformarse con una obra realizada en madera, lo que daba lugar a frecuentes pérdidas de agua y a gastos continuos en reparaciones ${ }^{35}$.

Tras obtener los derechos sobre el agua del Sotillo, y con motivo de la construcción del Palacio del Infantado, símbolo del poder de su linaje, el II duque del Infantado contrató en 1494 al maestro Alí Pullalte para comenzar las obras de una conducción más duradera que sustituyera a la primitiva de los frailes, una vez hubo conseguido el permiso eclesiástico para poder llevar los caños por el cementerio cercano a la iglesia

${ }^{35}$ LaYna Serrano, El palacio del Infantado en Guadalajara, pp. 82-83. 
de Santa María de la ciudad. Entendemos que la molestia de levantar las calles de la capital alcarreña obedecía a la necesidad de sustituir las viejas cañerías por otras más modernas y con mayor capacidad, si bien no es descartable que el duque decidiera construir una tubería paralela a la principal ya existente, de forma que tuviera pleno control sobre su propio caudal. Así, el alarife se obligó ante el duque a

Faser sesenta arcas desdel nascimiento de donde nasce el agua del Sotillo fasta las casas e palaçios de su señoría en guisa quel dicho maestre Aly eche en cada una de las dichas arcas una tenaja de obra de çinquenta cántaros de agua y questa dicha tenaja la meta debaxo de los caños que agora están de palo de pino y fecho el sytio de manera que pueda llevar e lleve un enforro de cal e ladrillo ${ }^{36}$.

\section{Unos días después, el mismo maestro se comprometió a}

Faser un arbollón dende entraviesa el agua que vyene de la fuente del Sotillo fasta una agua que mandó sacar Jorje Martínes en la cueva del Sotillo nuevo, desta guisa: quel dicho maestre alý lo abra de una açequia del hondo que fuere menester fasta el dicho nascimiento del agua, et que en esta dicha açequia haga un arbollón de ladrillo e cal del alto que de yuso se dirá e que luego eche un suel de ladrillo del gordo de un peme (sic) y ensomo deste suel haga sus paredes derechas de quatro hiladas de ladri$110^{37}$.

Esta conducción sería completada dos años más tarde, en 1496, cuando el duque del Infantado volvió a contratar al maestre Alí Pullalte para finalizar la obra, obligándose éste a llevar el agua hasta una de las salas del palacio, y de ahí a un estanque exterior ${ }^{38}$. Para ello, el proyecto contemplaba dos tipos de canalizaciones. La primera de ellas, que iría desde las fuentes del Sotillo hasta un punto cercano a la puerta de Bejanque, consistía en 12.000 tejas totalmente recubiertas de una estructura de cal y ladrillo por dentro de la cual viajaba el agua. La segunda parte del proyecto tomaba el agua desde Bejanque, y la llevaba al palacio del Infantado a través de un caño formado por 3.000 piezas cilíndricas de barro cocido, protegidas a su vez por una estructura de cal, arena, ladrillo y betún.

El proyecto definitivo se completó con el acuerdo firmado en 1500 entre los frailes de San Francisco y el III duque del Infantado, por el que éstos cedían al Mendoza la mitad del agua a la que tenían derecho en el Sotillo a cambio de que el duque se la transportara desde sus fuentes hasta un estanque cerca del monasterio, entendemos que haciendo uso de la construcción levantada por el maestro Alí por mandato de su padre el II duque del Infantado ${ }^{39}$.

La magnitud e importancia de la obra hidráulica realizada por los duques del Infantado fue tal que todavía en el siglo XVII el historiador Francisco de Torres, en su descripción de Guadalajara, dedica su atención a la traída de aguas del Sotillo en

36 Layna SERrano, Ibidem.

37 Layna Serrano, Ibidem.

38 AHN-SN, OSUNA, C. 2234, D. 1. Edit.: LAYna Serrano, Historia de Guadalajara y sus Mendozas en los siglos $X V$ y XVI, II,p. 491.

39 Layna Serrano, El palacio del Infantado en Guadalajara, p. 83. 
términos elogiosos, por cuyos conductos dice que podía caber un hombre a caballo, y a la que califica como "una de las mejores obras que hay en Castilla" describiéndola como "edificio de romanos, así lo denota la forma antiquísima de la fábrica y lo costoso y ostensivo de ellas ${ }^{40}$ ". La reseña del cronista, al igual que toda su obra, es exagerada en sus alabanzas a la ciudad, pero en cualquier caso, la consideración que le dedica a esta infraestructura, denominada posteriormente como viaje de Santa Ana, por ser éste el nombre del arrabal cercano a San Francisco, es un indicio de su importancia para Guadalajara, que se mantuvo durante toda la Edad Moderna ${ }^{41}$.

\section{LOS GASTOS DE CONSTRUCCIÓN Y MANTENIMIENTO DE LA INFRAESTRUCTURA RELACIONADA CON EL AGUA}

El sistema de canalización urbano que hemos descrito a lo largo de estas páginas era una infraestructura de gran envergadura que requería de un desembolso periódico para su mantenimiento. El correcto funcionamiento de las tuberías y las fuentes que servían a la ciudad era responsabilidad del concejo, si bien no existía un mantenimiento programado de las mismas, pues ningún oficio urbano tenía entre sus responsabilidades la vigilancia de esta infraestructura, sino actuaciones puntuales en casos de necesidad ${ }^{42}$. Esto provocaba que las reparaciones se llevaran a cabo solo cuando eran absolutamente imprescindibles, lo cual las hacía muy costosas por culpa del abandono de cualquier labor de mantenimiento preventivo durante los años anteriores.

La cuantía de estas obras de reparación, cuando eran necesarias, sobrepasaba con creces las rentas de propios disponibles del concejo, lo que obligaba a efectuar derramas entre los pecheros de la ciudad y las aldeas, que no eran por lo general bienvenidas por la población local. Un ejemplo de la importancia de las sumas requeridas por el concejo en ese sentido lo encontramos en la carta que los regidores mandaron en 1456 al concejo de Tendilla ${ }^{43}$, antigua aldea del alfoz arriacense, que en aquel momento ya era señorío de los Mendoza, en la que les reclaman, como antiguo lugar de

\footnotetext{
40 García López, Historia de la muy nobilissima ciudad de Guadalaxara dedicada a su illustrissimo ayuntamiento por don Francisco de Torres, su regidor perpetuo, año de 1647,p. 26-27.

${ }^{41}$ En la actualidad, y a pesar de las obras de desmonte acometidas para construir un viaducto sobre el barranco del Sotillo, todavía se puede encontrar una pequeña construcción de finales del siglo XVI que guardaba la fuente mayor que abastecía de agua a la ciudad, en cuya fachada principal se esculpieron las armas del V duque del Infantado (Herrera CASADO, "El arca del agua: un patrimonio a conservar").

${ }^{42}$ En ese sentido, Guadalajara muestra un menor grado de desarrollo urbano que ciudades como Valladolid, donde existía el oficio de "mayordomo de las labores del concejo", ayudado por un "obrero". (MonSALVO Anton, Sociedades urbanas y culturas políticas en la Baja Edad Media castellana, p. 40). Otro ejemplo es el de Almería, que contaba con limpiadores de los cauces de agua pagados por el concejo y por aquellas personas que se beneficiaban directamente de su trabajo (SEGURA GRAíño, "El abastecimiento de agua en Almería a fines de la Edad Media”, pp. 1005-1017).

${ }^{43}$ La villa de Tendilla, tras ser desgajada del realengo en 1394 por Enrique III (SÁnChEz PrIETO, La casa de Mendoza hasta el tercer duque del Infantado (1350-1531), p. 48), mantuvo varias disputas con el concejo de Guadalajara sobre temas diversos, destacando los conflictos por el uso de los terrenos comunales fronterizos (Plaza De Agustín, "La usurpación de tierras comunales y baldíos en Guadalajara durante la segunda mitad del siglo XV", pp. 459-485) y los pleitos derivados del derecho alegado por los vecinos de Tendilla de meter vino en la capital alcarreña, que los regidores arriacenses nunca aceptaron de buen grado, y que tensaron las
} 
su jurisdicción, 1.800 maravedíes para reparar la fuente de Santa María, los caminos de acceso a la ciudad, y las murallas ${ }^{44}$. Considerando el número de aldeas de Guadalajara, así como la población de la propia ciudad, y extrapolando la cantidad pedida a Tendilla a todos los vecinos de la Tierra de Guadalajara, cabe pensar que estamos ante una cantidad más que considerable que, como era de imaginar, el concejo de Tendilla se negó a pagar por no ser ya lugar de realengo, y por tanto no estar obligado a ello ${ }^{45}$.

Esta gestión puntual, carente de planificación alguna, se observa en algo tan sencillo como la limpieza de las fuentes, para la que los regidores optaban por contratar temporalmente a algún vecino que quisiera realizar el trabajo. Así, cuando las condiciones de la fuente, generalmente la de Santa María, por ser la principal de Guadalajara, se hacían insalubres por la cantidad de lodo acumulado, los regidores mandaban al pregonero de la ciudad que anunciase en la plaza del concejo la singular oferta de empleo, que se adjudicaba a aquel hombre dispuesto a cobrar menos dinero por realizar la labor ${ }^{46}$.

Otro elemento que requería la atención del concejo era el puente sobre el río Henares. En términos generales, en el siglo XV se observa una atención cada vez mayor a los puentes en Castilla, debido a su papel fundamental en el apoyo a las rutas trashumantes, y en ese sentido son muy comunes las obras de reparación y construcción en los reinados de Enrique IV y los Reyes Católicos ${ }^{47}$. Guadalajara no fue ajena a esta nueva mentalidad, y el 22 de julio de 1454 la ciudad se reúne para debatir la situación del edificio, que necesitaba reparaciones urgentes debido a su lamentable estado de conservación.

El puente se erigía en uno de los símbolos de la ciudad, cuya importancia como vía de comunicación, fuente de recaudación fiscal, y elemento de prestigio está fuera de toda duda, por lo que la reparación para evitar su derrumbe era un asunto de la máxima importancia para Guadalajara. Así, los regidores propusieron una derrama a la ciudad para conseguir los fondos necesarios ${ }^{48}$. Los caballeros y escuderos arriacenses protestaron, al considerar que las rentas de propios del concejo eran suficiente recurso para pagar la reparación, algo a lo que se negaban los regidores, alegando que los propios debían usarse para los gastos ordinarios de la ciudad, y no para los extraordinarios. Finalmente, se decidió convocar a todos los vecinos en asamblea al día siguiente, para que votase si procedía realizar o no un repartimiento con el que sufragar la reparación ${ }^{49}$. Después de muchos debates, tanto los caballeros y escuderos

relaciones de ambos municipios durante la segunda mitad del siglo XV (López ViLLALbA, "El abastecimiento del vino y su política proteccionista en el alto Tajo (siglos XIV-XV)", pp. 143-184).

${ }^{44}$ AMGU, 138892 Edit.: López Villalba, Fuentes históricas de Guadalajara. Archivo Municipal de Guadalajara, II, p. 145.

${ }^{45}$ AMGU, 138892 Edit.: LóPEZ Villalba, Fuentes históricas de Guadalajara. Archivo Municipal de Guadalajara, II, p. 146.

${ }^{46}$ A modo de ejemplo: AMGU 1H 0084A, LA, 1475, f. 11r. Edit.: LóPEZ Villalba, Las actas de sesiones del concejo medieval de Guadalajara, p. 166.

47 Diago Hernando y Ladero Quesada, "Caminos y ciudades en España de la Edad Media al siglo XVIII", pp. 347-382.

${ }^{48}$ AMGU, 1H 0084A, LA, 1454, f. 17v. Edit.: López Villalba, Las actas de sesiones del concejo medieval de Guadalajara, p. 119.

${ }^{49}$ AMGU, 1H 0084A, LA, 1454, f. 18v. Edit.: LóPez VillalbA, Las actas de sesiones del concejo medieval de Guadalajara, p. 122. 
como los miembros del Común accedieron a realizar una derrama de 60.000 maravedíes, que se sumarían a los que el concejo debía recibir del pago de herbajes pasados, así como otras rentas que no eran de propios. Cantidades, como se puede apreciar, nada desdeñables, que la ciudad debía aportar cada cierto tiempo para mantener el puente que le daba el control sobre el comercio de la comarca.

El caso de puente sobre el Henares es un ejemplo muy claro de cómo durante la segunda mitad del siglo XV los gastos de mantenimiento y reparación en la ciudad se fueron incrementando. El caso alcarreño no es distinto al de otras ciudades castellanas, como Segovia, donde los gastos generados por las reparaciones provocaron derramas continuas que tomaron prácticamente el carácter de ordinarias ${ }^{50}$. En ambas ciudades la cuantía a invertir era tan importante que se hacía necesario combinar ingresos de las rentas de propios, las derramas y recaudaciones de multas para conseguir el montante necesario.

\section{EL RÍO HENARES}

El Henares tuvo durante la Edad Media una importancia estratégica para Guadalajara. Sin embargo, a diferencia de muchas otras ciudades castellanas, el río apenas sirvió como fuente de suministro de agua para los vecinos de la ciudad, posiblemente por la dificultad que implicaba elevar el agua hasta lo alto de la loma donde se ubica el municipio ${ }^{51}$, y prueba de ello es que el tejido urbano se fue desplazando a lo largo de la Edad Media hacia el Sur, cada vez más lejos del Henares, buscando un terreno más llano. En ese sentido es interesante comprobar cómo lo que había sido el núcleo original de la Guadalajara musulmana, muy cerca del río, fue quedando cada vez más deshabitado, hasta convertirse en poco más que un pequeño barrio casi despoblado que ni siquiera quedó incluido dentro del trazado de la muralla definitiva, creándose un espacio suburbano que separaba físicamente el Henares de la Guadalajara amurallada, cuyos arrabales crecían hacia el lado contrario, posiblemente porque era preferible construir en las tierras elevadas, de mejor defensa y peor calidad de suelos, y dejar la ribera derecha del río, donde el terreno era más productivo, para tareas agrícolas.

En todo caso, a pesar de que el río no se usaba apenas para abastecimiento humano, su cauce era de gran importancia para la economía local. En primer lugar, la actividad pesquera, si bien no puede compararse con la ganadería o la agricultura locales, debió tener cierta relevancia, pues es regulada por las ordenanzas del concejo, y generaba rentas para la ciudad en forma de tasas que se cobraban por permitir la pesca a particulares $^{52}$. Ciertamente, esta práctica iba contra el espíritu de la legislación medieval

\footnotetext{
50 Asenjo González, Segovia: la ciudad y su Tierra a fines del medievo, p. 468.

51 Guadalajara presentaba una problemática similar a la de otras ciudades construidas en altura sobre un río cercano, como Toledo. La diferencia entre ambas localidades radica en que mientras Guadalajara contaba con agua potable de manantiales cercanos situados a una mayor altura que la ciudad, en Toledo el agua del Tajo era el único suministro apto para el consumo humano, lo que obligó a los toledanos a establecer un sistema de acarreo de agua desde el río a las viviendas usando la fuerza animal que era innecesario en la capital alcarreña (IzQuierdo Benito, "El agua en Toledo en la Edad Media", pp. 211-240).

${ }^{52}$ Layna Serrano, Historia de Guadalajara y sus Mendozas en los siglos XV y XVI, II,p. 502.
} 
castellana, y específicamente de las Partidas ${ }^{53}$, verdadera referencia legal en lo que a bienes comunales se refiere, que considera a los cauces de agua como espacios de uso público y gratuito para todos los vecinos de forma conjunta ${ }^{54}$. A través de las ordenanzas de 1346 conocemos también la costumbre existente en las cercanías de la ciudad de construir pequeñas presas en el río Henares, que servían para remansar el agua de forma que pudiera aprovecharse fácilmente para el riego o la pesca ${ }^{55}$.

El río Henares ya contaba con algún molino harinero en el término de Guadalajara al menos desde principios del siglo XIII, pues en el Fuero Largo otorgado por Fernando III a la villa en 1219 se regula el tramo del río que queda bajo el control del dueño del molino "Tod ome que molino oviere defienda de la presa arriba, quanto una piedra pudiere echar; et del cauze ayuso, otros y defienda quanto una piedra pudiere

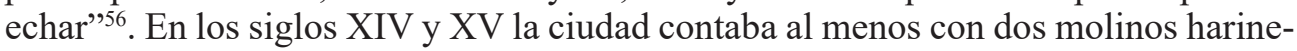
ros en sus cercanías, uno de los frailes de Lupiana y otro de los del Paular, así como dos batanes (denominados "el viejo" y "el nuevo"), que demuestran cierta intensidad en el uso del cauce fluvial como recurso económico ${ }^{57}$.

La presencia de estos molinos en el Henares no estuvo exenta de conflictos, pues los dueños de los mismos trataban de controlar el espacio cercano, ya fueran vados, abrevaderos o simplemente las riberas del río, en detrimento del derecho que tenían los vecinos a su uso. En ese sentido, destaca la disputa relacionada con el molino harinero ubicado en las cercanías de Fontanar ${ }^{58}$, en el término conocido actualmente como Haza del Fraile, donde cruza el río la carretera que une las localidades de Fontanar y Tórtola de Henares. Este edificio, que controlaba uno de los pocos vados que permitían atravesar el cauce en aquella zona, estaba en funcionamiento desde al menos finales del siglo XIV, y era propiedad de los frailes de San Bartolomé de Lupiana. La importancia de este lugar, que servía como zona de paso, así como abrevadero para los ganados, provocó varios pleitos entre la ciudad y los frailes del monasterio, quienes emplearon todos sus medios para conservar el uso exclusivo de la zona para sus ganados, prohibiendo que los vecinos de la Tierra de Guadalajara accedieran a ella, y generando varios conflictos a lo largo del siglo XV, pues el concejo consideraba que el vado era de uso público, y debía quedar abierto.

La disputa afectaba también a los derechos de pesca en el tramo del río entre Guadalajara y Fontanar, que el monasterio consideraba que le pertenecían en exclusiva, algo que los vecinos de Guadalajara y sus aldeas nunca aceptaron. Los litigios entre ambas partes, que habían comenzado en 1421, continuaron hasta 1490, cuando se decide llegar a un acuerdo satisfactorio para todos, por el cual el señorío sobre el río en el tramo en disputa quedaba para la ciudad, si bien el monasterio se reservaba el monopolio de la pesca en todo el cauce a cambio del desembolso de 650 maravedíes

${ }^{53}$ Partida III, Título 28, Ley 6, (Las Siete Partidas del rey don Alfonso el Sabio, II, p. 711).

${ }^{54}$ Son muy interesantes en ese sentido las reflexiones sobre las Partidas de Bonachía Hernando, "El agua en las Partidas", pp. 13-64.

${ }^{55}$ López Villalba, "Política local y abastecimiento urbano: el pescado en Guadalajara en la Baja Edad Media", pp. 221-244.

${ }^{56}$ Martín Prieto, Fueros de Guadalajara, p. 44.

${ }^{57}$ A modo de ejemplo: AMGU, 1H 0084A, LA, 1454, f. 3v. Edit.: LóPeZ ViLlalba, Las actas de sesiones del concejo medieval de Guadalajara, p. 74.

${ }^{58}$ Archivo Histórico Nacional, Clero Secular-Regular, 2146. 
anuales, que los frailes hicieron pagaderos mediante dos censos perpetuos sobre inmuebles en la ciudad. A cambio de este derecho, los vecinos de Guadalajara y sus aldeas podían usar los abrevaderos y vado sobre el Henares en aquel tramo sin temor de ser detenidos por los guardas del monasterio. Ciertamente, la importancia del monopolio de la pesca no debía ser un asunto menor para los frailes, quienes habían invertido mucho dinero en crear "canales y otros artifiçios para tomar pescado en las dichas tablas del rio e sus corrientes", que demuestran una explotación sistemática de la riqueza pesquera del Henares.

El monasterio de San Bartolomé de Lupiana no fue el único que construyó canales en el cauce del río para su explotación. También los frailes del Paular, en los terrenos que poseían en las cercanías de Fontanar, realizaron algunas inversiones para extraer el máximo provecho a la corriente en las cercanías de su molino, situado en el camino entre Guadalajara e $\mathrm{Hita}^{59}$. El monasterio del Paular tuvo pleitos similares con la ciudad a los ya mencionados para el molino de San Bartolomé de Lupiana en los últimos años del siglo XV, pues en este caso los dueños del molino también aprovecharon su propiedad para vedar el acceso a los abrevaderos cercanos, lo cual fue protestado por los regidores arriacenses, que consideraban que la presencia de un molino no podía privar a los habitantes de la zona del acceso a un bien comunal, como era el cauce de agua. Las investigaciones realizadas por varios jueces de términos permiten comprobar la existencia de varios canales habilitados para el riego de las tierras cercanas, así como de un puente de madera.

La presencia de propiedades privadas en las riberas del río, como los molinos mencionados de ambos monasterios, o una finca de los duques del Infantado, suponía un problema para la convivencia diaria, pues los propietarios de estas tierras impedían de forma recurrente el acceso de los ganados de los vecinos a los abrevaderos del Henares, lo que generaba serios conflictos cuando los guardas al cargo de estos lugares procedían contra los pastores como si de delincuentes se tratase. En ese sentido, la ciudad fue muy beligerante con la defensa de esos espacios públicos, lo cual está en línea con la existencia de intereses ganaderos de la oligarquía local, que copaba los puestos de responsabilidad del concejo.

Todo el siglo XV está salpicado de pleitos en los que la ciudad trata de proteger la categoría de bienes concejiles de los abrevaderos, y exige a los jueces de términos competentes que señalen los accesos a los mismos, de forma que se eviten conflictos. Podemos, sin tratar de ser exhaustivos, poner varios ejemplos ilustrativos, como el caso de la alquería del Cañal, muy cerca del río Henares, entre Guadalajara y Fontanar, en la que Fernando de Torres, despensero del rey, intentó a principios del siglo XV crear un término redondo prohibiendo el acceso de los vecinos al agua, y especialmente a dos abrevaderos públicos. La ciudad se vio obligada a iniciar un proceso judicial dirigido por un juez de términos enviado a la zona en 1434, quien obligó a Fernando de Torres a abrir el acceso de los ganados al río ${ }^{60}$. Otro caso muy interesante es el pleito entre el concejo de Guadalajara y las hijas del duque del Infantado, Ana y Leonor, que tuvo lugar en 1494, en el que la ciudad acusa a las nobles de haber tapiado una fuente y un abrevadero en el camino entre Guadalajara y el

59 AMGU, 133137.

${ }^{60}$ AHN-SN, OSUNA C. 1874 D. 25. 
ahora despoblado de Benalaque, situado a escasos kilómetros al Suroeste de la capital alcarreña, muy cerca del Henares, y que concluyó con la orden del juez de términos de derribar la cerca que impedía el acceso al agua ${ }^{61}$. Un tercer caso muy significativo lo encontramos en Fontanar, donde el Juez de términos Diego de Salmerón devuelve al concejo en 1503 nada menos que cuatro abrevaderos del río Henares tomados por particulares. Este último ejemplo nos sirve para conocer que los espacios calificados como abrevaderos en el río Henares eran delimitados mediante mojones de cal y canto, dejando entre ellos un tramo de río de entre cincuenta y sesenta pasos, dentro de los cuales el acceso de los ganados era libre y gratuito. Así, en uno de los cuatro abrevaderos mencionados para el caso de Fontanar se menciona lo siguiente:

E fizieron sendos mojones junto con el camino real que va de Guadalajara a Hita el uno de un cabo del abrevadero e el otro del otro e quedó el abrevadero en medio tan ancho e desocupado como dixo el dicho juez que era de derecho e en derecho de aquello sobre las barranqueras del rio se fisieron otros dos mojones uno junto con otro mojón que estava allí de cal e canto e en derredor e que se fiso e otro mojón así quedó abierto al dicho abrevadero de la dicha parte de hasia Fontanar ${ }^{62}$

Además de su función agrícola, ganadera y pesquera, para el concejo de Guadalajara como institución de gobierno local el río tenía, sobre todo, una importancia fiscal, pues el puente de la ciudad, única vía permanente para cruzar el Henares, se convertía en el punto de recaudación de los pertinentes impuestos al paso de mercancías y ganados. Es muy ilustrativa en ese sentido la iniciativa tomada por el monasterio de San Bartolomé de Lupiana en 1485. Los frailes, cansados de tener que pagar cada vez que sus ganados cruzaban el puente, decidieron instalar una barca para su uso particular ${ }^{63}$. Los regidores de Guadalajara, alarmados por este hecho, que podía sentar un precedente peligroso para las arcas municipales, trataron de negociar con los frailes, llegando a un acuerdo por el que la ciudad tomaba posesión de la barca, que cedió en arriendo a un particular, el cual se comprometía a dar el transporte de forma gratuita a los frailes, y a cobrar un maravedí por cada hombre o animal que quisiera cruzar el río de esa manera. Así, la ciudad mantenía el monopolio del control del paso de personas y ganados en sus cercanías ${ }^{64}$.

\section{CONCLUSIONES}

Lo expuesto hasta ahora muestra un claro interés por parte de los poderes religiosos y nobiliarios de la ciudad en desarrollar la red local de abastecimiento de agua para provecho propio, tanto por razones prácticas como por motivos de prestigio. Este suministro, proveniente de las fuentes del reborde del páramo alcarreño, cuyo caudal

\footnotetext{
${ }^{61}$ AMGU, 138893.

${ }^{62}$ AMGU, 133137.

${ }^{63}$ AMGU, 1H 0084A, LA, 1485,f. 10v. Edit.: López Villalba, Las actas de sesiones del concejo medieval de Guadalajara, p. 23.

${ }^{64}$ AMGU, 1H 0084A, LA, 1485, f. 29v. Edit.: López Villalba, Las actas de sesiones del concejo medieval de Guadalajara, p. 273.
} 
fue siempre limitado, requería fuertes inversiones que solo los Mendoza podían sufragar. Éstos utilizaron su influencia sobre el regimiento así como su riqueza para obtener del concejo el derecho de explotación de las fuentes del Sotillo, las principales de la ciudad, que pasaron así de ser un bien de disfrute comunal a un recurso casi privado controlado por la casa del Infantado y por los monasterios urbanos que protegía, de cuyo caudal quedaba apenas una pequeña parte para uso público en las fuentes de Santa María y San Andrés, intramuros de Guadalajara.

Junto con las fuentes del Sotillo, el río Henares se configura como un elemento hídrico indispensable para la ciudad, no tanto por su valor como fuente de agua potable, sino por los usos ganaderos, agrícolas, pesqueros e industriales que tenía. La importancia del río en la vida de la ciudad se refleja en los continuos conflictos que el concejo y el monasterio de San Bartolomé de Lupiana mantuvieron por su control y que se alargaron durante buena parte del siglo XV.

El concejo de la ciudad, por su parte, descuidaba la infraestructura hidráulica de la localidad. En ese sentido, tanto las reparaciones periódicas, como la inversión en nuevas obras, se discutían en el momento en el que se éstas se hacían imperiosas, sin planificación alguna, siendo el asunto de la financiación una de las cuestiones más difíciles de solucionar, como ya se ha comprobado en los casos en los que los Mendoza trataron, infructuosamente, de realizar canalizaciones desde fuentes cercanas contando con la colaboración de la ciudad.

Finalmente, es preciso mencionar que se observa un cambio paulatino en la mentalidad del citado concejo respecto a las obras públicas que se manifiesta ya claramente en las dos últimas décadas del siglo XV, sin duda gracias a la intensa labor de mecenazgo ejercida por los Mendoza, y a la llegada de numerosas familias hidalgas a la ciudad, que tenían interés en el ennoblecimiento del espacio intramuros. El fenómeno es similar al de muchas otras ciudades castellanas, que se dotan en estos años de finales de la Edad Media de infraestructuras y magníficos edificios religiosos y civiles ${ }^{65}$. En esa línea, los esfuerzos por mejorar el abastecimiento de agua potable en estos años, liderados por los magnates mendocinos, son un claro ejemplo de esta nueva mentalidad que refleja la existencia de un patriciado urbano que asociaba su prestigio al de la ciudad donde residía.

\section{BIBLIOGRAFÍA}

Asenjo González, María, Segovia: la ciudad y su Tierra a fines del medievo, Segovia: Excelentísima Diputación Provincial de Segovia, 1986.

Barragán Muñoz, Juan Manuel (coord.), Agua, ciudad y territorio: aproximación geohistórica al abastecimiento de agua a Cádiz, Cádiz: Universidad de Cádiz, 1993.

BlázquEz, Álvaro, Mapa hidrológico de la provincia de Guadalajara, Guadalajara: Diputación de Guadalajara, 2010.

Cuadrado Prieto, Miguel Ángel, Arenas Esteban, Jesús Alberto Y Crespo Cano, María Luz, "Estudio preliminar de la secuencia estructural del Alcázar de Guadalajara", en García-Soto Mateos, Ernesto, García Valero, Miguel Ángel y Martínez Naranjo,

${ }^{65}$ Ver nota 1. 
Juan Pablo (coords.), Actas del Segundo Simposio de Arqueología de Guadalajara: Molina de Aragón, 20-22 de abril de 2006, Sigüenza: Centro de Profesores de Sigüenza, 2006, pp. 279-298.

Diago Hernando, Máximo y Ladero Quesada, Miguel Ángel, “Caminos y ciudades en España de la Edad Media al siglo XVIII”, En la España Medieval, 33, (2010), pp. 347-382.

Diges Antón, Juan, Guía del turista en Guadalajara, Guadalajara: Taller tipográfico de la Casa de Expósitos, 1914.

García Jiménez, María Antonia (coord.), Crónicas del agua. La importancia del agua en nuestra cultura, Madrid: Ministerio de Medio Ambiente, 2009.

GARCía LóPEz, Aurelio (estudio, comentario, transcripción y edición), Historia de la muy nobilissima ciudad de Guadalaxara dedicada a su illustrissimo ayuntamiento por don Francisco de Torres, su regidor perpetuo, año de 1647, Madrid: Bornova, 2011.

Hernández, Francisco Javier, Los cartularios de Toledo. Catálogo documental, Madrid: Fundación Ramón Areces, 1985.

Herrera CASADO, Antonio, "El arca del agua: un patrimonio a conservar", Nueva Alcarria, 5/1/1990. (http://www.herreracasado.com/1990/01/05/el-arca-del-agua-un-patrimonioa-conservar/)

IzQuiERdo Benito, Ricardo, "El agua en Toledo en la Edad Media", en VAl VAldivieso, María Isabel y Bonachía Hernando, Juan Antonio (coords.), Agua y sociedad en la Edad Media Hispana, Granada: Universidad de Granada, 2012, pp. 211-240.

Jiménez AlCÁzAr, Juan Francisco, Agua y poder en Lorca durante la Baja Edad Media, Murcia: Universidad de Murcia, 1996.

JiMÉNEZ RAYADO, Eduardo, "El abastecimiento de agua en Madrid durante la Edad Media", en Val Valdivieso, María Isabel y Bonachía Hernando, Juan Antonio (coords.), Agua y sociedad en la Edad Media Hispana, Granada: Universidad de Granada, 2012, pp. 241-273.

Las Siete Partidas del rey don Alfonso el Sabio. Tomo 2, ed. de la Real Academia de la Historia, Madrid, 1807.(http://fama2.us.es/fde/lasSietePartidasEd1807T2.pdf)

LaYna Serrano, Francisco, Historia de Guadalajara y sus Mendozas en los siglos XV y XVI, Guadalajara: Aache Ediciones, 1994.

Layna Serrano, Francisco, El palacio del Infantado en Guadalajara, Guadalajara: Aache Ediciones, 1997.

Layna Serrano, Francisco, Los conventos antiguos de Guadalajara, Guadalajara: Aache Ediciones, 2010.

Lopez Villalba, José Miguel, Las actas de sesiones del concejo medieval de Guadalajara, Madrid: U.N.E.D., 1997.

López Villalba, José Miguel, Fuentes históricas de Guadalajara. Archivo Municipal de Guadalajara. Vol. II (1436-1459), Madrid: Universidad de Alcalá, 2007.

López Villalba, José Miguel, "Política local y abastecimiento urbano: el pescado en Guadalajara en la Baja Edad Media", Studia historica, Historia medieval, 25, (2007), pp. 221-244.

López Villalba, José Miguel, "El abastecimiento del vino y su política proteccionista en el alto Tajo (siglos XIV-XV)", Espacio, Tiempo y Forma, Serie III, Historia Medieval, 24, (2011), pp. 143-184. 
Luis López, Carmelo, Fuentes históricas de Guadalajara. Archivo Municipal de Guadalajara. Vol. III (1460-1473), Madrid: Universidad de Alcalá, 2007.

Luis López, Carmelo, Fuentes históricas de Guadalajara. Archivo Municipal de Guadalajara. Vol. IV (1474-1485), Madrid: Universidad de Alcalá, 2008.

Martín Prieto, Pablo, Fueros de Guadalajara, Guadalajara: Diputación Provincial de Guadalajara, 2010.

Monsalvo Anton, José María, Sociedades urbanas y culturas políticas en la Baja Edad Media castellana, Salamanca: Ediciones Universidad de Salamanca, 2013.

Oliva Herrer, Hipólito Rafael, "L'eau et le pouvoir dans les villes castillanes à la fin du Moyen Âge. Palencia, un exemple de concurrence de pouvoirs", Histoire Urbaine, 22, (2008), pp. 59-75.

Parejo Delgado, María Josefa, "El abastecimiento urbano en Baeza y Úbeda en la Baja Edad Media", en CARA BARRIONUEVo, Lorenzo (coord.), El agua en zonas áridas. Arqueología e historia. Hidráulica tradicional de la provincia de Almería, Almería: Instituto de Estudios Almerienses, 1989. pp. 813-836.

Pavon Maldonado, Basilio: Guadalajara medieval: arte y arqueología árabe y mudéjar, Madrid: Consejo Superior de Investigaciones Científicas, 1984.

Plaza De Agustín, Javier, "La usurpación de tierras comunales y baldíos en Guadalajara durante la segunda mitad del siglo XV", Espacio, Tiempo y Forma, Serie III, Historia Medieval, 28, (2015), pp. 459-485.

Pradillo Estéban, Pedro José, “Organización del espacio urbano en la Guadalajara medieval", Wad-al-Hayara: Revista de estudios de Guadalajara, 15, (1999), pp. 215-246.

SÁnchez León, Pablo, Absolutismo y comunidad. Los orígenes sociales de la guerra de los comuneros de Castilla, Madrid: Siglo XXI de España Editores, 1998.

SÁnCHEZ Prieto, Ana Belén, La casa de Mendoza hasta el tercer duque del Infantado (13501531). El ejercicio y alcance del poder señorial en la Castilla bajomedieval, Madrid: Palafox \& Pezuela, 2001.

Segura Graíño, Cristina, "El abastecimiento de agua en Almería a fines de la Edad Media", En la España medieval, 5, (1984), pp. 1005-1017.

Segura Graíño, Cristina, Agua y sistemas hidráulicos en la Edad Media hispana, Madrid: Asociación Cultural Al-Mudayna, 2003.

Serrano Bertos, Elena, Torra Pérez, María del Mar, Castro Priego, Manuel, Sánchez GonzÁLEz, Aurelia, "Excavaciones en Guadalajara: secuencia andalusí desde época emiral a taifa y presentación de un singular conjunto numismático", Arqueología y territorio medieval, 11, (2004), pp. 79-114.

VAL VALDIVIESo, María Isabel (coord.), Usos sociales del agua en las ciudades hispánicas de la Edad Media, Valladolid: Secretariado de Publicaciones e Intercambio Editorial de la Universidad de Valladolid, 2002.

VAl VAldivieso, María Isabel, Agua y poder en la Castilla bajomedieval. El papel del agua en el ejercicio del poder concejil a fines de la Edad Media, Valladolid: Junta de Castilla y León, 2003.

Val Valdivieso, María Isabel y Villanueva Zubizarreta, Olatz, Musulmanes y cristianos frente al agua en las ciudades medievales, Cuenca: Universidad de Castilla-la Mancha, 2009. 
Val Valdivieso, María Isabel y Bonachía Hernando, Juan Antonio (coords.), Agua y sociedad en la Edad Media Hispana, Granada: Universidad de Granada, 2012.

VV.AA.: Auditoría de sostenibilidad del municipio de Guadalajara, Guadalajara: Cátedra de Medio Ambiente de la Universidad de Alcalá, 2006, (http://www.guadalajara.es/es/ ayuntamiento/Medio-Ambiente-2/Descarga-Documentos\&iddocumento=2647). 